Uluslararası Mühendislik

International Journal of

Engineering Research and

Development

10.29137/umagd.747710

Cilt/Volume:12 Sayı/Issue:2 Haziran/June 2020

Araştırma Makalesi / Research Article

\title{
The Importance of Energy Quality in Medical Devices and Evaluation of Measurements Made in Kurıkkale University Medical Faculty MRI Device within the Scope of TS EN 50160I
}

\author{
Emre Metin $^{1}$ iD, Özgür Karagülle ${ }^{1}$ iD, Kardelen Kamişli' $^{1}$ iD, Ertuğrul Çam *2 iD \\ ${ }^{1}$ AES Innovation, Kırlkkale Üniversitesi Teknopark, 71450, Kırlkkale, TURKEY \\ ${ }^{2}$ Kirlkkale University, Department of Electrical \& Electronics Engineering, 71450, Klrkkkale, TURKEY
}

Başvuru/Received: 13/05/2020

Kabul / Accepted: 07/06/2020

Çevrimiçi Basım / Published Online: 30/06/2020

Son Versiyon/Final Version: 30/06/2020

\begin{abstract}
Today, the increase in demand for electrical energy has revealed a more reliable and higher quality energy concept. This subject has taken its place in electrical engineering as "Power Quality" or "Electric Energy Quality" and has made a point for its importance with the studies on it. Especially in the process of working with devices containing electronic circuits with direct current and using the alternating current offered from the network by using rectifiers, the devices may fail or become disabled due to self-protection circuits in case of power quality problems arising from the mains or the rectifiers of the device. In this article, a detailed analysis is carried out considering the problem may be due to the power quality due to the fact that the MRI device in Kirikkale University Faculty of Medicine is in continuous failure mode. In addition, the analyzes made in accordance with TS EN 50160 standard within the scope of the research were analyzed in computer environment and the results were shared in our article. In this article, the relationship between power quality problems and grounding is also examined.
\end{abstract}

Key Words

"energy analysis, 50160, flicker, crest factor" 


\section{Introduction}

Although statistical information about electrical energy quality is limited, most problems have been identified in recent years. The most common problems are; harmonic components that can last from a few seconds to a few hours, complete power outages (voltage depressions), voltage fluctuations where the voltage reaches very low or high values, semiconductor technology widespread in all areas, the power factor desired to be at least 0.95 , even when talking with the mobile phone, relay tripping problems electromagnetic interactions that can result.

As the reasons for more frequent mention of energy quality issues in recent years, the following can be said.

- There are problems affecting the whole system instead of local problems due to interconnected systems,

- Industrial users who are renewed with microprocessor and power electronics components are more likely to experience the effects caused by minor non-standard fluctuations in voltage,

- Competitions for producing higher quality energy among producers,

- Consumers begin to be more sensitive and knowledgeable about power quality issues.

The most common energy quality problems in the network can be listed as follows:

- Voltage disturbances

- Voltage drop (Dip-Sag)

- Voltage rise (Swell)

- Voltage Deduction (Outages)

- Transients

- Notch

- Voltage Fluctuations, Flicker

- Regular or irregular step voltage changes (Welding and rolling machines are caused by tunnel or mine ventilation systems.)

- Regular or irregular voltage changes (Arc furnaces)

- Distortion caused by harmonic components

- Voltage harmonics

- Current harmonics

- Notches

- Imbalances (Unbalances)

- Electromagnetic Interference (EMI)

- $\quad$ Noise (Noise)

In this article, measurements on the causes of frequent malfunctions of MRI devices at Kirıkkale University Medical Faculty were analyzed with the equipment purchased with the project numbered 2019/166 supported by Kirikkale University BAP. The results showed that the Faculty grid's energy quality problems are not large enough to affect MRI devices, and device problems are mostly caused by user errors. (Anderson \& Fouad,1994), (NEMA, 1996), (NFPA 70, 2011), (Arrillaga \& Arnold,1990), (Arrillaga et al., 1985)

\section{Background of the Electrical Energy Quality Problems}

In practice, there is always a close relationship between current and voltage in any power system. Although generators generate voltage very close to the sine wave, currents passing through the impedance of the system can cause various disturbances in the voltage. For example;

- The current resulting from a short circuit may cause the voltage to drop or the voltage to collapse completely.

- Currents resulting from lightning strikes can cause high-impact voltages in the power system, causing "high-impact voltages".

- The distorted currents formed by harmonic generating loads pass the system impedance and also disturb the voltage and thus, the customers are fed with a distorted voltage. (Arrillaga et al., 1997), (Berg,1978).

In Table 1, it is seen that the weather conditions are mainly caused by voltage depressions and interruptions in the power line. Also, in the same table, it is seen that voltage depressions affect the computer systems four times more negatively than interruptions. In addition to these, transient events are very important for the systems. The term "Transient" has been used for a long time to indicate an undesirable and instantaneous event in the analysis of power systems. Transient events are very short-lived (up to a few milliseconds) voltage distortions, but their intensity is very high and the rise is very fast. Most temporary events are caused by lightning strikes, large loads, and reactive loads. Transient states can be classified under two categories as pulsed and oscillating. These terms reflect the waveform of the current and voltage transient state. Generally, protection systems keep temporary effects below a certain level of security. If the place where temporary events occur is close to the installation or inside the installation, problems may arise(Sankaran, 2001), (Chapman, 2001), (Domijan \& Embriz-Santander,1992). 
Table 1. Causes of computer system failures due to network disruptive effects

\begin{tabular}{lccc}
\hline \multicolumn{1}{c}{ Causes } & \multicolumn{2}{c}{ Disruptive Effects } & $\begin{array}{c}\text { Computer } \\
\text { System Failures }\end{array}$ \\
& Breakdowns & Outages & \\
\hline Weather Conditions & 37 & 14 & 51 \\
Power System Failures & 8 & 0 & 8 \\
Traffic Accidents & 8 & 2 & 10 \\
Living beings & 5 & 1 & 6 \\
Tree felling & 1 & 1 & 2 \\
Unknown & 21 & 2 & 23 \\
TOTAL & $\% 80$ & $\% 20$ & $\% 100$ \\
\hline
\end{tabular}

These problems can be listed as follows:

- The damage caused can be very sudden,

- Installation or equipment repairs can be damaged in an impossible way,

- The data on the computer may disappear,

- The effects can be repeated over time and damage the insulation of the materials. (Dugan, et al., 1996), (Kwasnicki et al., 2004)

As a result of these accumulations, much larger damages may occur. Costs to take measures are relatively low. The precautions to be taken can be listed as follows:

- A low impedance grounding system with a wide frequency range should be selected, with a good low impedance connection in the ground electrode system.

- The design of lightning protection systems should be done appropriately, taking into account local factors such as determining the number of days when lightning events occur per year.

- Protection systems should be located in the first entrance of the incoming line, including telephone and other communication lines.

- Organizations manufacturing protection systems should also provide protection against temporary events occurring in switching devices. (Dommel, 1969), (HPQ,1996)

The transient event is also defined as a sudden change in the steady-state condition without a frequency of power in both voltage and current parameters that are one-way (positive or negative) in terms of polarity. They are normally characterized by pulsed transient events, rising and delay times. Pulse-like transients can stimulate the natural frequencies of power systems circuits and produce transient states. In these cases, the systems have oscillations, mostly. The oscillation is defined as a sudden change in the frequency of power of both voltage and current parameters containing non-unidirectional positive and negative polarity values. Oscillation transients include currents and voltages whose sudden values quickly change polarity. They are characterized by frequency content, amplitude, and duration. The commissioning of capacitor groups in turn will cause the formation of transient currents in the form of oscillations. Commissioning and disconnecting wired lines with breakers will also cause voltage transients to oscillating in the same frequency region. (Radatz, 1998)

Additionally, some voltage changes can occur in the power systems due to their characteristics, too. These changes can last long or short term. The ANSI C84.1 standard clearly states the steady-state voltage tolerances in a power system. When the ANSI limits are exceeded by values greater than 1 minute, the voltage change is considered for a "long term". Long-term changes can be in the form of overvoltage or undervoltage. Overvoltage and low voltages are not generally the result of system failures, but they can occur due to load changes in the system and on-off events in the network. However, short term changes include the voltage drops (dips) and short voltage cuts according to the International Electrotechnical Commission IEC. Short-term voltage changes occur because of the malfunctions. Also, energizing large loads that have high starting current is another reason for this situation. Sometimes, it also occurs due to the short-term non-contact in the fasteners. Depending on the location of the malfunction and the state of the system, the malfunction may temporarily cause a voltage drop, rise, or cut off voltage completely. The malfunction may be near or far from 
the point of interest. In both cases, the effect on the voltage during the breakdown is a short-term change until the protection relays come on and clear the fault. (Lamoree et al., 1991)

Power frequency variations, another problem, are expressed as deviations from the fundamental frequency of the power system, determined by nominal values of $50 \mathrm{~Hz}$. or $60 \mathrm{~Hz}$. Power system frequency is directly related to the angular velocity of the generators feeding the system. When the dynamic balance between load and production changes, insignificant changes occur in frequency. The magnitude and duration of the deviation in frequency depending on the load characteristics and the response of the production control system to the load changes. Frequency changes can cause the failure of a large part of the transmission system, large-scale loads, or large-power generators to fail if the power system goes beyond the limits accepted for normal steady-state operation. In this case, the system has to be black-out. The distortion of the waveform is in principle steady from the ideal sine wave-shaped power frequency, which is characterized by the spectral content of the deviation. It is expressed as aberration. There are basically five different waveform distortions: These are DC component, harmonics, intermediate harmonics, notch, noise and voltage fluctuation. Electromagnetic Interference (EMI) is a small energy distorting wave with amplitude between $100 \mu \mathrm{V}$ and $100 \mathrm{~V}$, frequency between $10 \mathrm{kHz}$ and 1 GHz. Switched power supplies arise from motor control circuits, radio broadcasts and communications over power lines. For this purpose, the examination of the MR waveform becomes important (Frank,1997), (Schwartzenberg et al., 1995), (Kennedy, 2000), (Kocatepe et al., 2003), (Ludbrook, 1993), (McGranaghan, 1981), (McGranaghan \& Mueller, 1999).

\section{MRI Waveform Type}

A wide range of gradient waveforms is utilized for MR imaging. The most common waveforms include trapezoidal, triangular, and sinusoidal. MR gradient heating depends on the time derivative of the gradient waveform and on-device shape, size, and conductivity of its conductive elements and applied gradient frequency content. Experiments have been performed using simple structures, e.g. cylindrical disk, showing that a critical frequency can be identified over which heating becomes less due to inductive effects. In order to maximize the amount of power deposited, a low-frequency sine waveform is proposed to evaluate device heating when exposed to gradient fields present in an MR scanner. A sine waveform does not contain higher-order harmonics present in the triangle or trapezoidal waveforms. Because of this all of the power induced on a test article will be focused at the frequencies not attenuated by device inductive effects. It is known that frequency dependence exists related to gradient-induced device heating. As frequency decreases below a certain critical frequency, device heating might be maximized. Thus, it is desired to determine the lowest possible clinically relevant frequency which a device might experience in an MR scanner assuming a sine wave gradient signal. Using a sine wave test signal, the $B \mathrm{G}(\mathrm{t})$ function can be described as follows: (Cenelec, 2014)

$B G(t)=B G \times \sin (2 \pi \times f \times t)$

where

$B G$ is the magnitude of the gradient field in the MR scanner and bench test coil, in T;

$f$ is the frequency, in $\mathrm{Hz}$;

$t$ is time, in $\mathrm{s}$.

By differentiating the formula above with respect to time, the following formula is produced:

$$
\frac{d B_{G}(t)}{d t}=2 \pi \times f \times B_{G} \times \cos (2 \pi \times f \times t)
$$

From this formula, the $d B / d t$ _rms value can be determined as:

$$
\left(\frac{d B_{G}(t)}{d t}\right)_{\mathrm{rms}}=\frac{2 \pi \times f \times B_{G}}{\sqrt{2}}
$$

From the values previously discussed, we have:

$$
42 \frac{\mathrm{T}}{\mathrm{s}}=\frac{2 \pi \times f \times(35 \mathrm{mT})}{\sqrt{2}}
$$

Solving for frequency produces the following result: 


$$
f=\frac{\left(42 \frac{\mathrm{T}}{\mathrm{s}}\right) \times \sqrt{2}}{2 \pi \times(0,035 \mathrm{~T})}=270 \mathrm{~Hz}
$$

The sine wave frequency for alternative values are shown in Table 2 .

Table 2. The sine wave frequency for alternative values

\begin{tabular}{cc}
\hline $\begin{array}{c}B G \\
\text { mT }\end{array}$ & Frequency Hz \\
\hline 60 & 158 \\
50 & 189 \\
40 & 236 \\
35 & 270 \\
30 & 315 \\
20 & 473 \\
\hline
\end{tabular}

Due to test system $B \mathrm{G}$ limitations, it might not be possible to test at the required

$$
\begin{aligned}
& \left(\frac{d B_{G}(t)}{d t}\right)_{\text {rms }} \text { value. In this case, it is acceptable to apply a } B G \text { waveform of the same frequency with } \\
& \left(\frac{d B_{G}(t)}{d t}\right)_{\text {rms }}\left(\frac{d B_{G}(t)}{d t}\right)_{\text {rms }} \text {. }
\end{aligned}
$$

\section{Power Quality Standards: TS EN 50160 and TS EN 61000-4-30}

\subsection{TS EN 50160}

The object of this European Standard is to define, describe and specify the characteristics of the supply voltage concerning:

a) frequency;

b) magnitude;

c) waveform;

d) symmetry of the line voltages.

These characteristics are subject to variations during the normal operation of a supply system due to changes of load, disturbances generated by certain equipment and the occurrence of faults which are mainly caused by external events. The characteristics vary in a manner which is random in time, with reference to any specific supply terminal, and random in location, with reference to any given instant of time. Because of these variations, the values given in this standard for the characteristics can be expected to be exceeded on a small number of occasions. Some of the phenomena affecting the voltage are particularly unpredictable, which make it very difficult to give useful definite values for the corresponding characteristics. The values given in this standard for the voltage characteristics associated with such phenomena, e.g. voltage dips and voltage interruptions, shall be interpreted accordingly. (IEEE, 1995), (Series, 2014)

\subsection{TS EN 61000-4-30}

This part of IEC 61000-4 defines the methods for measurement and interpretation of results for power quality parameters in a.c. power supply systems with a declared fundamental frequency of $50 \mathrm{~Hz}$. or $60 \mathrm{~Hz}$. Measurement methods are described for each relevant parameter in terms that give reliable and repeatable results, regardless of the method's implementation. This standard addresses measurement methods for in-situ measurements. Measurement of parameters covered by this standard is limited to conducted phenomena in power systems. The power quality parameters considered in this standard are power frequency, magnitude of the supply voltage, flicker, supply voltage dips and swells, voltage interruptions, transient voltages, supply voltage unbalance, voltage harmonics and interharmonics, mains signalling on the supply voltage, rapid voltage changes, and current measurements. (I. E. C., 2015)

\subsubsection{Classes of measurement}

For each parameter measured, two classes, A and S, are defined in this standard. For each class, measurement methods and appropriate performance requirements are included. 


\section{- Class A}

This class is used where precise measurements are necessary, for example, for contractual applications that may require resolving disputes, verifying compliance with standards, etc. Any measurements of a parameter carried out with two different instruments complying with the requirements of Class A, when measuring the same signals, will produce matching results within the specified uncertainty for that parameter. Synchronization of aggregation intervals for Class A you can see Figure 1

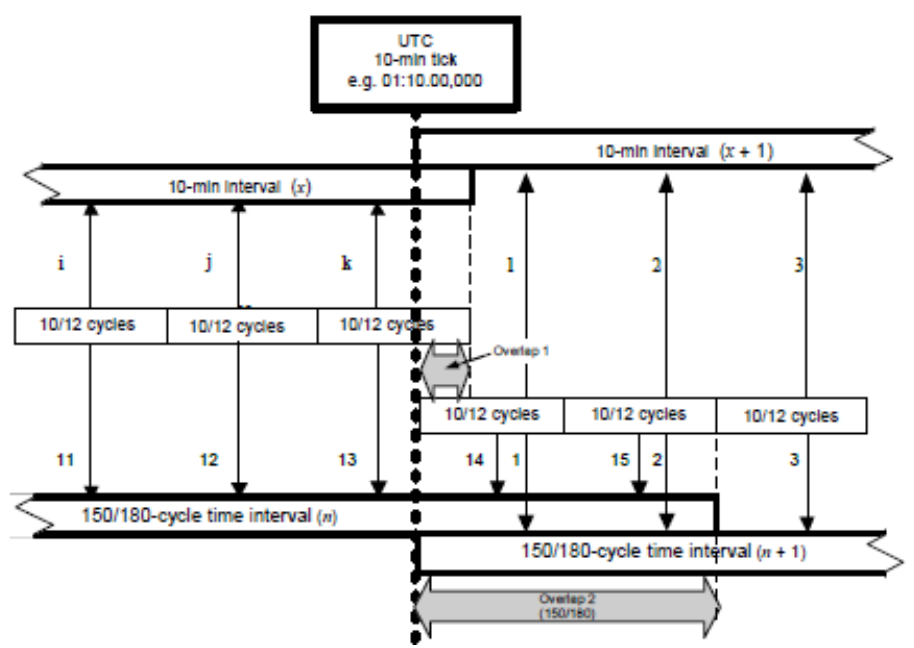

Figure 1. Synchronization of aggregation intervals for Class A

\section{- Class S}

This class is used for statistical applications such as surveys or power quality assessment, possibly with a limited subset of parameters. Although it uses equivalent intervals of measurement as Class A, the Class S processing requirements are much lower. Some surveys may assess power quality parameters of several measurement sites on a network; other surveys assess power quality parameters at a single site over a period of time, or at locations within a building or even within a single large piece of equipment.

\section{- Class B}

For Class B information, see Annex E (informative) of this standard. Class B methods shall not be employed for new instruments. Class B is moved to Annex E on the basis that all new instrument designs will comply with either Class A or Class S. Class B may be relevant for legacy instruments that are still in use. Class B may be removed in the next edition of this standard.

\subsubsection{Rapid voltage change (RVC)}

An RVC event is generally an abrupt transition between two r.m.s. voltages. By definition, the two r.m.s. voltages must be "steady state", a condition that is defined in the method below.

Dips and swells often begin or end with abrupt transitions between two r.m.s. voltages. However, by definition these are not RVC events because they exceed the dip or swell thresholds. Figure 2.

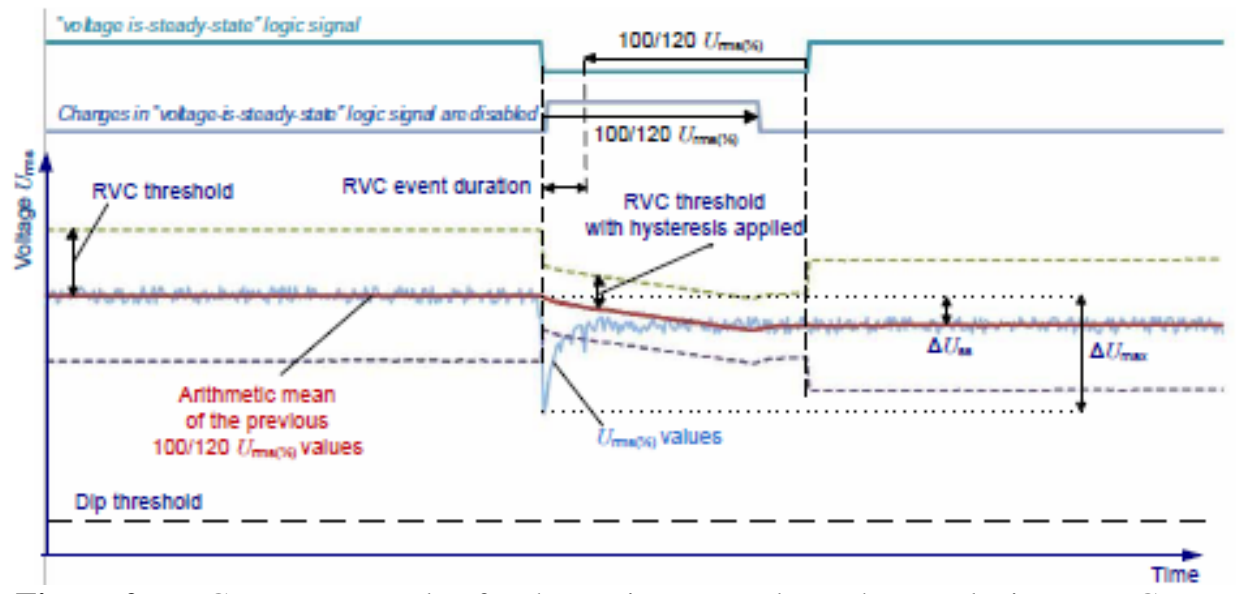

Figure 2. RVC event: example of a change in r.m.s voltage that results in an RVC event 


\section{Harmonic Limits}

For Class A equipment, the harmonics of the input current shall not exceed the values given in Table 3.

Table 3. Limits for Class A equipment

\begin{tabular}{|c|c|}
\hline $\begin{array}{c}\text { Harmonic order } \\
\qquad \text { h }\end{array}$ & $\begin{array}{l}\text { Maximum permissible } \\
\text { harmonic current } \\
\text { A }\end{array}$ \\
\hline \multicolumn{2}{|c|}{ Odd harmonics } \\
\hline 3 & 2,30 \\
\hline 5 & 1,14 \\
\hline 7 & 0,77 \\
\hline 9 & 0.40 \\
\hline 11 & 0.33 \\
\hline 13 & 0.21 \\
\hline $15 \leq h \leq 39$ & $0,15 \frac{15}{h}$ \\
\hline \multicolumn{2}{|c|}{ Even harmonics } \\
\hline 2 & 1,08 \\
\hline 4 & 0.43 \\
\hline 6 & 0.30 \\
\hline $8 \leq h \leq 40$ & $0.23 \frac{8}{6}$ \\
\hline
\end{tabular}

\section{About Power Quality Measurement}

According to EMRA Regulation on Service Quality Regarding Electricity Distribution and Retail Sale; Regarding the recording of technical quality parameters, the devices to be used must measure Class A specifications specified in the TS EN 61000-4-30 standard. Measurements will be made at OG and AG levels. Measurements will be carried out in locations where general assessment can be made through sampling to ensure different network characteristics and load profiles, customer groups, network sections that serve different population densities, from the network sections with the highest short circuit currents to the lowest network conditions.

\section{Measurement Equipment}

Portable power analyzer for measuring and recording all electrical parameters in singlephase, two-phase and three-phase networks. Measures leakage currents, power quality parameters and records transients. AR6 is an integral tool for problem diagnosis and detection in any electrical installation and can also be used to prepare energy studies. Technical features are high-accuracy energy-consumption studies, detection of problems relating to electrical protection elements, analysis of power quality and transient phenomena, local recording of start-up currents and other variables of interest on the unit.

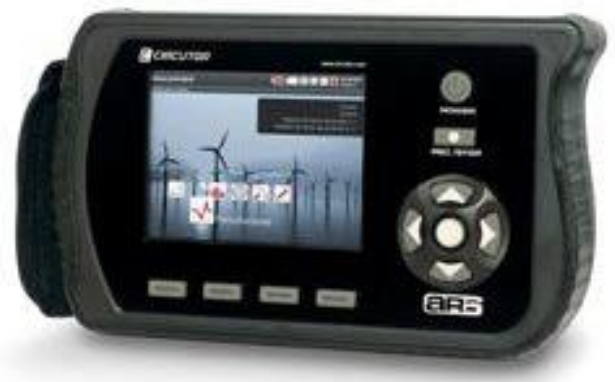

Figure 3. Circutor AR6 Class A Power Analyzer 


\section{Measurement Data}

Measurement results are as follows. Figure 4, Figure 5, Figure 6, Figure 7, Figure 8. Phase-Neutral voltage value tolerances (T) were found to be $\mathrm{T}<10 \%$. It has been observed that these tolerance values are suitable for devices and equipment that contain sensitive electronic structures. The voltage tolerance values declared by the manufacturers for the device containing sensitive electronic structures should be taken into consideration and, if necessary, they should be supplied via online power supplies. UPS tested has been found to have UPS in Figure 4.

MULTIGRAPHIC

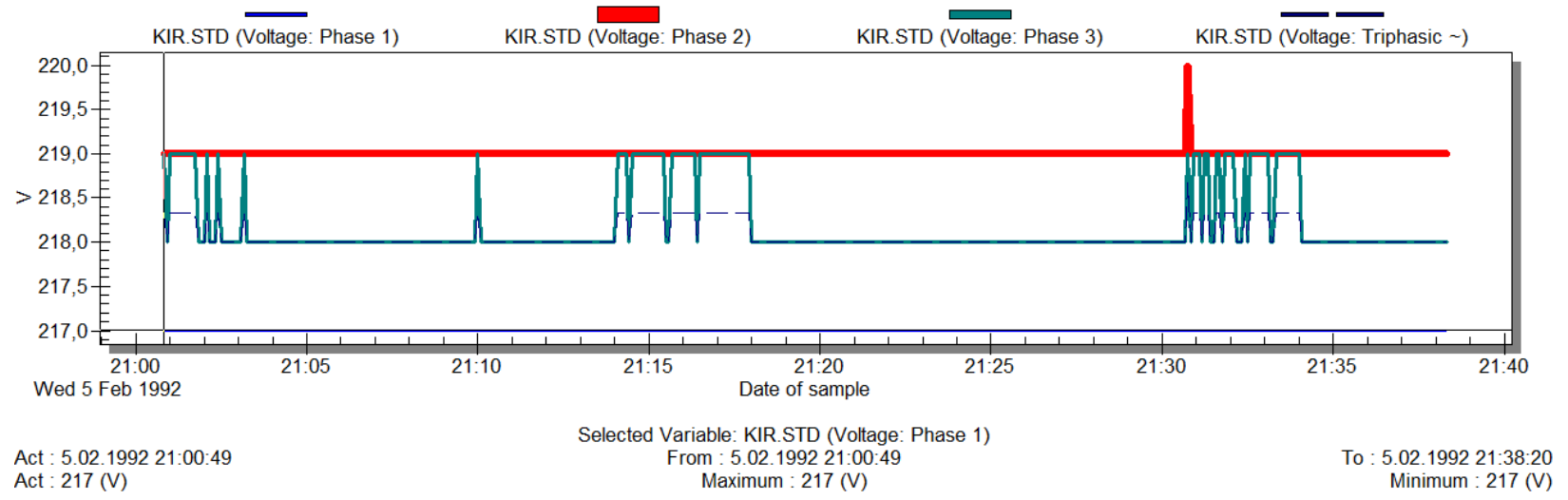

Figure 4. Voltage Graphic

5 min. records obtained in periods, we can state that the amount of current drawn in the system reaches 4.7A levels and an abnormality cannot be seen in Figure 5.

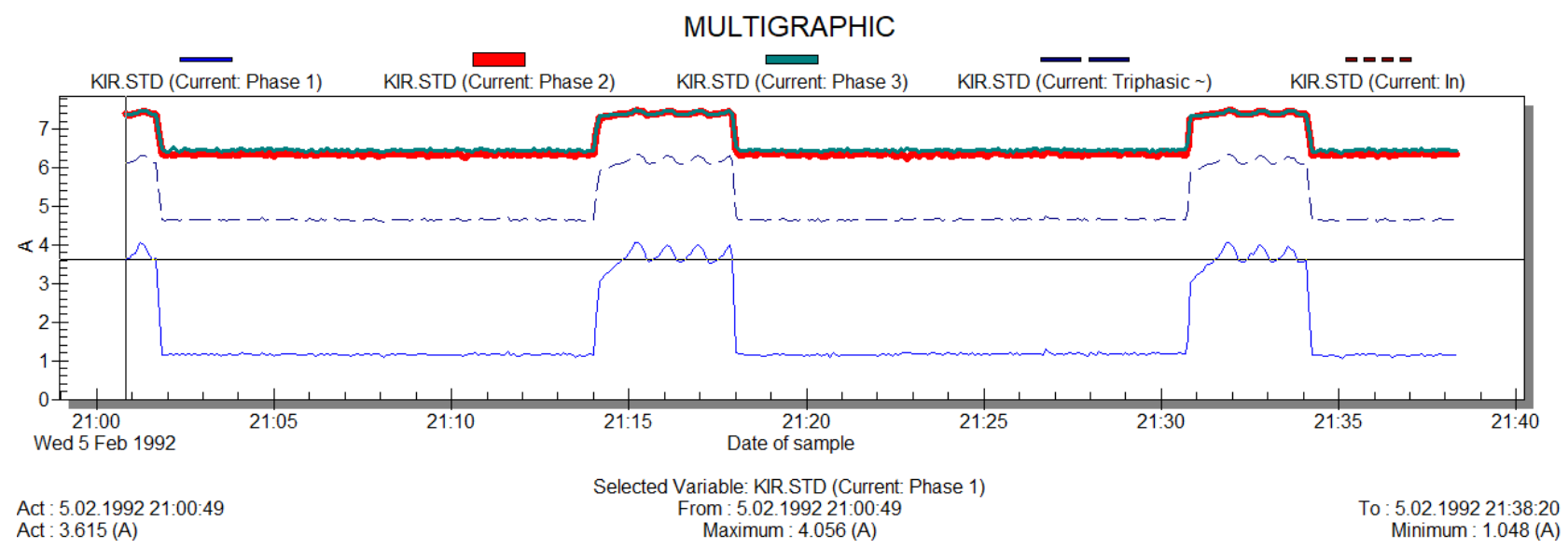

Figure 5. Current Graphic

It has been observed that the compensation system is generally sufficient for the observed time period in Figure 6 .

MULTIGRAPHIC

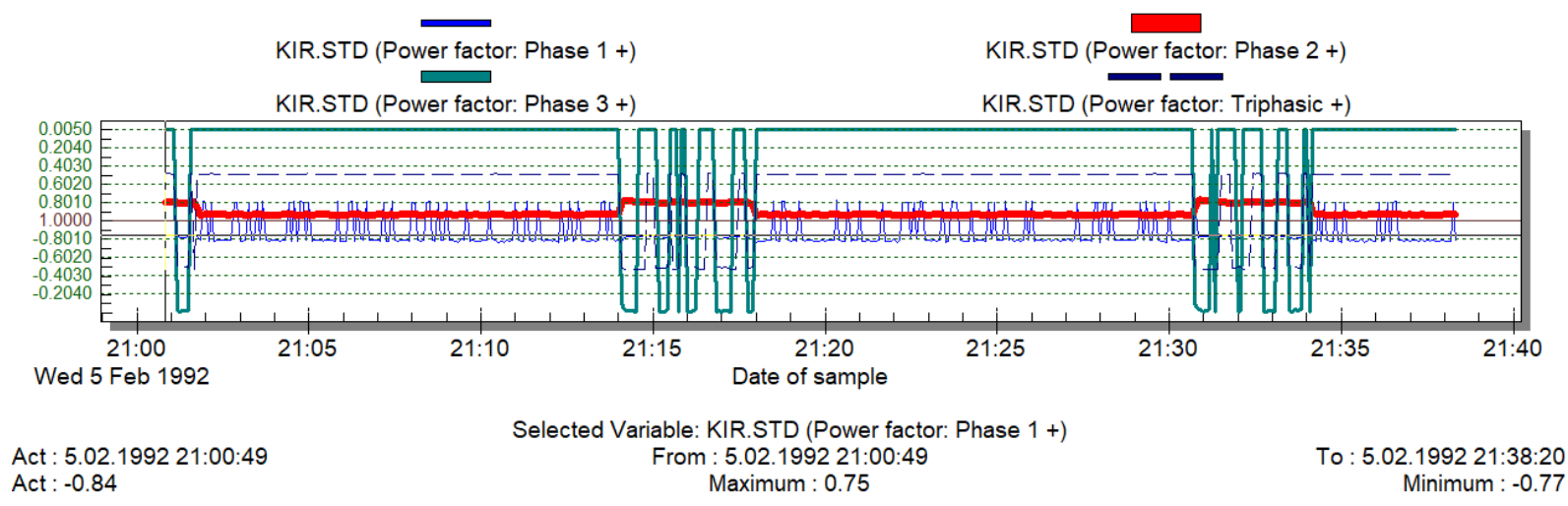

Figure 6. Power Factor Graphic 
As seen in Table 6, the total voltage harmonics are around 2\% and below the limit value (5\%) that EN 50160, ANSI / IEEE-519-1992 and EMRA predict. No fault is anticipated due to the total voltage harmonics. Total current harmonics (TTB = total demand distortion) exceed the 20\% value predicted in EMRA and IEEE-519. It is seen that the current total harmonic distortion level in A2 phase reaches up to $26,70 \%$. Depending on the current harmonics, sensitive devices have the risk of malfunction in Figure 7.

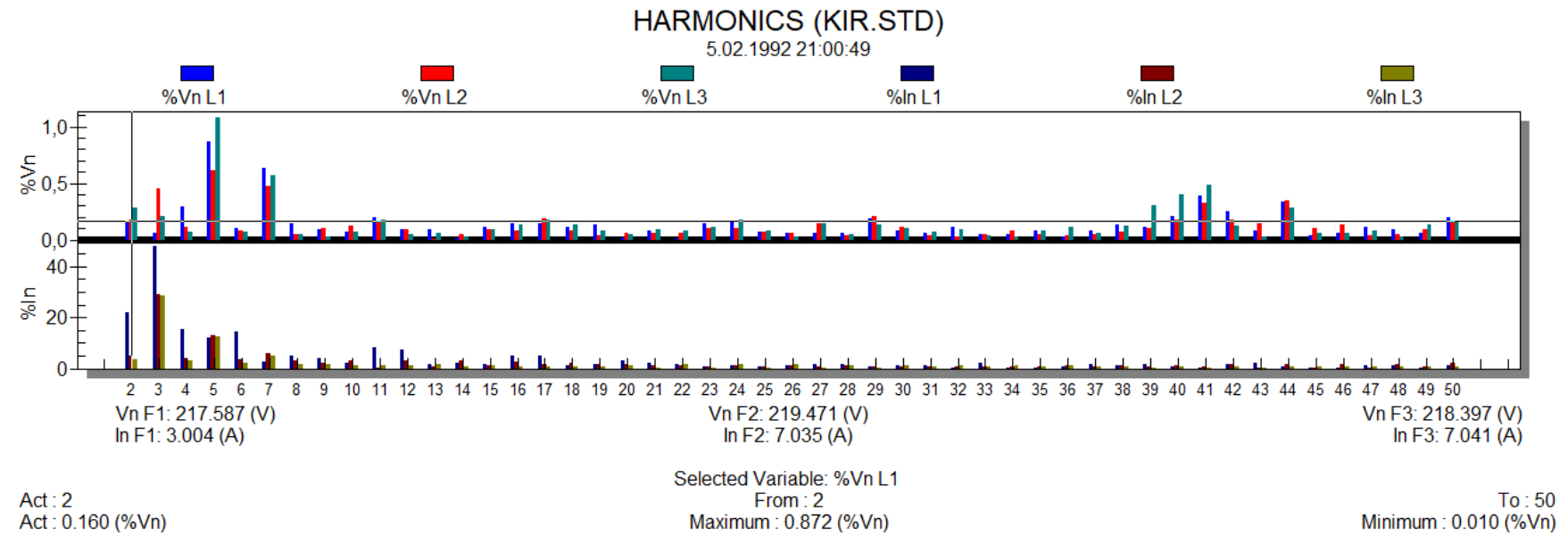

Figure 7. Harmonics Graphic

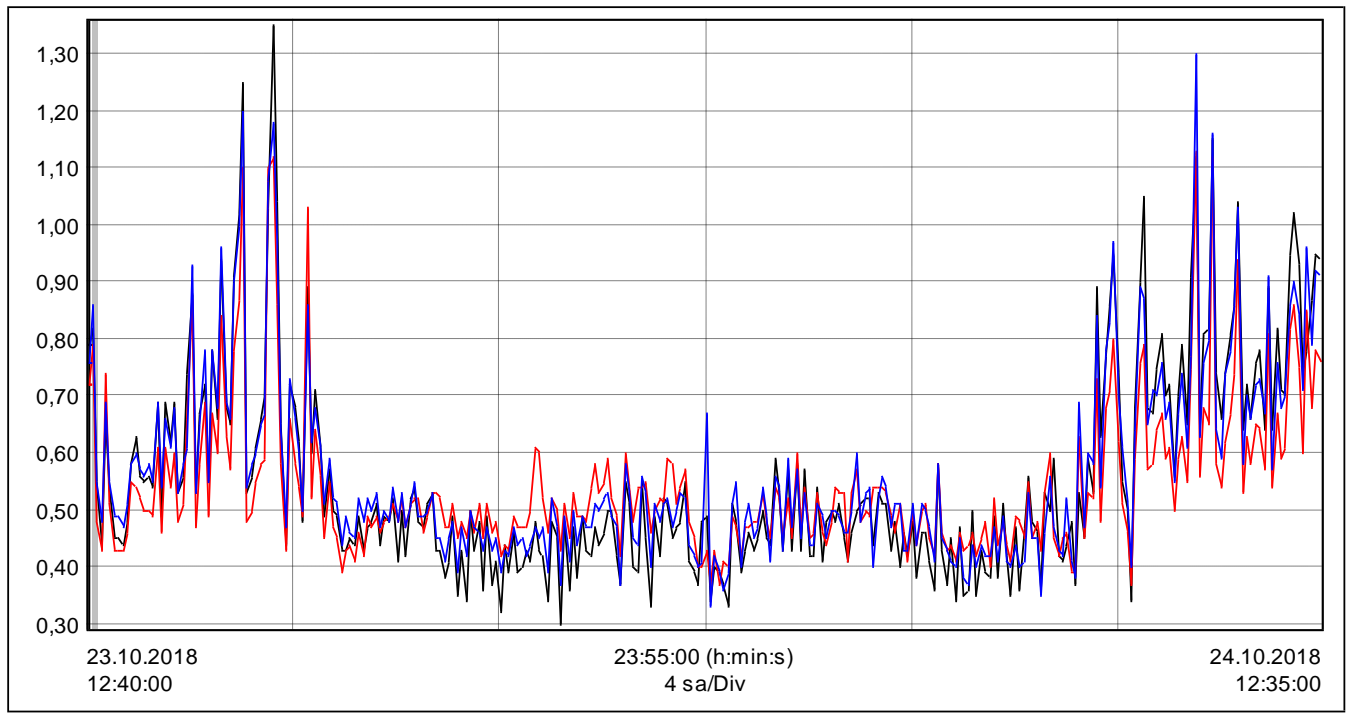

Figure 8. Flicker

Although the short-term flicker (in Figure 8) values detected were instantaneously above the limit values, they were generally found appropriate. No adverse effects are expected on medical equipment.

\section{Acknowledgements}

This project (2019/16) was supported by Kirıkkale University BAP. We would like to thank Kirıkkale University BAP for their contribution.

\section{Conclusions And Future Work}

According to the results of the measurement performed at the Energy input, UPS output and UPS input of the Kirikkale University Faculty of Medicine MRI device, it was understood that there was no network-related harmonic, flicker problem, but the energy quality problem shown as the reason that the device constantly switched to Quench mode, and the problem was caused by the helium gas leakage of the MRI device. Also, according to the measurement results, it was observed that there was no grounding deficiency. In 
medical locations it is necessary to ensure the safety of patients likely to be subjected to the application of ME (medical electrical) equipment. For every activity and function in a medical location, the particular requirements for safety have to be considered. Safety can be achieved by ensuring the safety of the installation and the safe operation and maintenance of ME equipment connected to it. The use of ME equipment on patients undergoing critical care has called for enhanced reliability and safety of Electrical installations in hospitals so as to improve the safety and continuity of supplies which is met by application of standards. In the later stages of the study, besides energy analysis, ROI analyzes will be carried out and a solution will be produced for high-end devices such as MRI.

\section{References}

Anderson, P.M., FOUAD, A.A., (1994), Power System Control and Stability, Revised Printing, IEEE Press, 1994.

Arrillaga, J., Bradley, D.A. ve Bodger, P.S., (1985), Power System Harmonics, John Wiley \& Sons, Norwich.

Arrillaga, J. ve Arnold, C.P., (1990), Computer Analysis of Power Systems, John Wiley \& Sons, Essex.

Arrillaga, J., Smith, B.C., Watson, N.R. ve Wood, A.R., (1997), Power System Harmonic Analysis, John Wiley \& Sons.

BERG G.J., "Assestment of critical voltage and load margins in VAR compensated power transmission systems", electric power system research, 12,pp.63-69,1978

Cenelec, E. N. (2014). 50160: Voltage characteristics of electricity supplied by public distribution systems. Cenelec, Brüssel.

Chapman, D. 2001. Güç Kalitesi Uygulama Kılavuzu, Copper Development Association, Sarkuysan Elektrolitik Bakır Sanayi ve Ticaret A.Ş. , İstanbul.

Domijan, A., \& Embriz-Santander, E. (1992). A novel electric power laboratory for power quality and energy studies: training aspects. IEEE transactions on power systems, 7(4), 1571-1578.

Dommel, H. W. (1969). Digital computer solution of electromagnetic transients in single-and multiphase networks. IEEE transactions on power apparatus and systems, (4), 388-399.

Dugan, R.C., McGranaghan, M.F., Beaty, H.W., “Electrical Power Systems Quality”, McGraw-Hill, 1996.

EM Committee. (1995). IEEE recommended practice for monitoring electric power quality. IEEE Std, c1-81.

Frank, J. M. (1997). Origin, development, and design of K-factor transformers. IEEE Industry Applications Magazine, 3(5), 67-69.

Home Power Quality, http://energyoutlet.com/res/powerqual/index.html, Energy Outlet, Iris Communications, Inc, USA, 1996.

Kennedy, B. W. (2000). Power quality primer. McGraw Hill Professional.

Kocatepe, C., Uzunoğlu, M., Yumurtacı, R., Karakaş, A., \& Arıkan, O. (2003). Elektrik Tesislerinde Harmonikler. Birsen Yayınevi, Istanbul.

Kwasnicki, W. T., Fernando, I. T., \& Gole, A. M. (2004). Modeling of Conventional and Advanced Static Var Compensators In An Electromagnetic Transients Simulation Program. Winnipeg, Canada.: sn.

Lamoree, J., Smith, J. C., Vinett, P., Duffy, T., \& Klein, M. (1991, October). The impact of voltage sags on industrial plant loads. In First International Conference on Power Quality, PQA (Vol. 91).

Ludbrook, A. (1993). Manager's guide to electrical power quality. Iron and Steel Engineer;(United States), 70(5).

McGranaghan, M. F., Shaw, J. H., \& Owen, R. E. (1981). Measuring voltage and current harmonics on distribution systems. IEEE Transactions on Power Apparatus and Systems, (7), 3599-3608.

McGranaghan, M. F., \& Mueller, D. R. (1999). Designing harmonic filters for adjustable-speed drives to comply with IEEE-519 harmonic limits. IEEE transactions on industry applications, 35(2), 312-318.

National Electrical Manufacturers Association. (1996). American National Standard for Electric Power Systems and EquipmentVoltage Ratings (60 Hertz). National Electrical Manufacturers Association. 
National Fire Protection Association. (2011). NFPA 70: National Electrical Code. NationalFireProtectionAssoc.

Radatz, J. (1998). The IEEE standard dictionary of electrical and electronics terms. IEEE Standards Office

Sankaran C., "Power Quality", CRC Pres, 2001.

Schwartzenberg, J. W., \& De Doncker, R. W. (1995, October). $15 \mathrm{kV}$ medium voltage static transfer switch. In IAS'95. Conference Record of the 1995 IEEE Industry Applications Conference Thirtieth IAS Annual Meeting (Vol. 3, pp. 2515-2520). IEEE.

Series, T. F. (2014). Glossary and definitions of time and frequency terms.

Std, I. E. C. (2015). 61000-4-30: 2015. Electromagnetic Compatibility (EMC)-Part, 4-30.

Warren, C. M. (1992). The effect of reducing momentary outages on distribution reliability indices. IEEE Transactions on power delivery, 7(3), 1610-1617. 